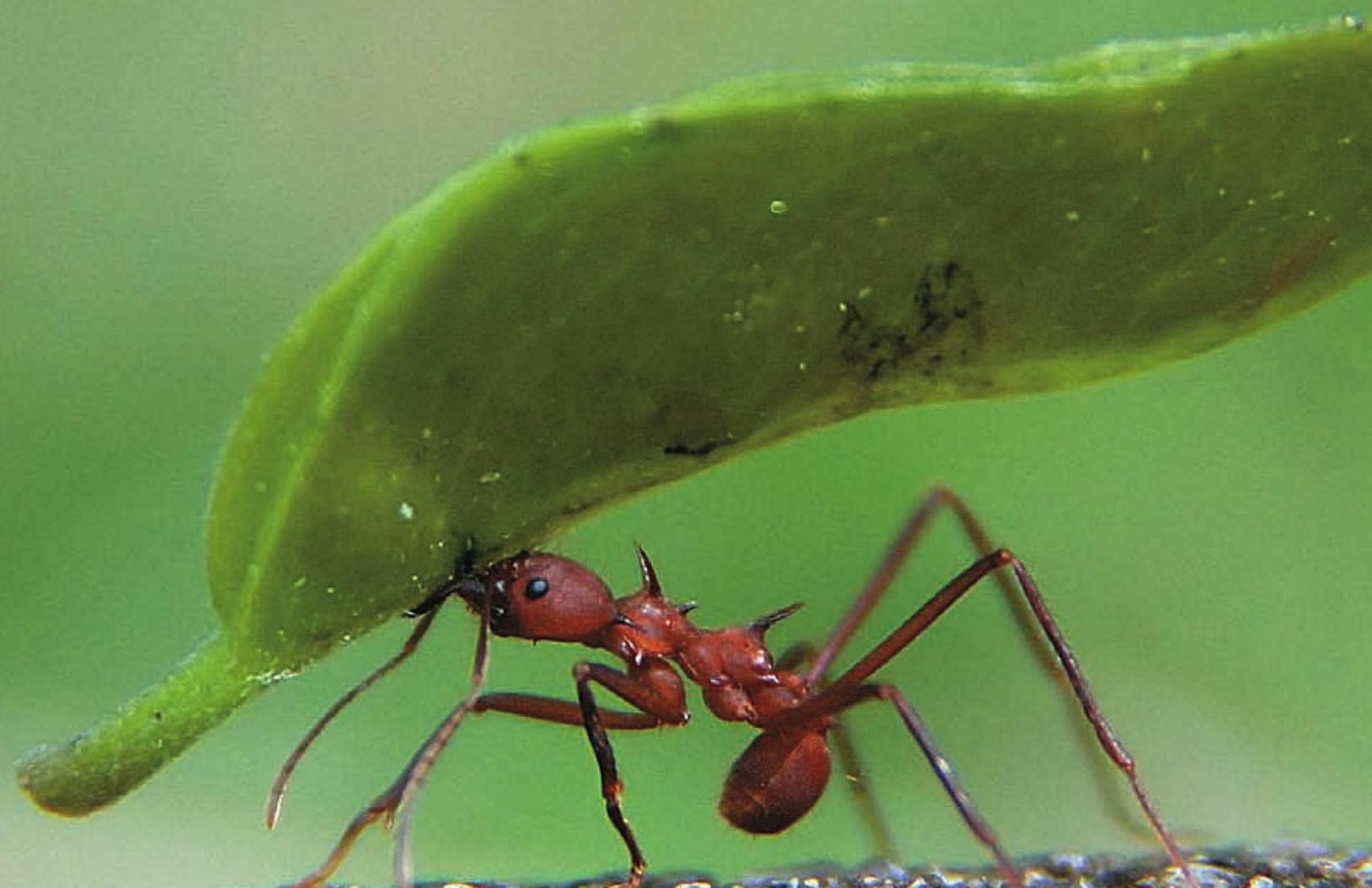

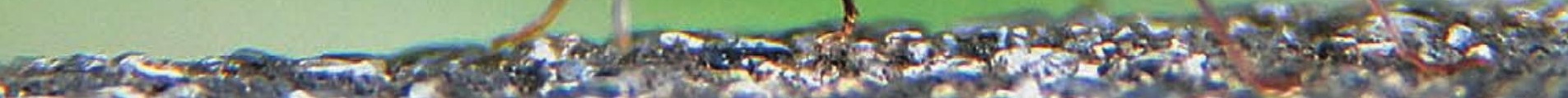

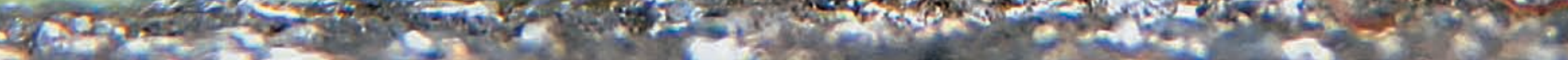

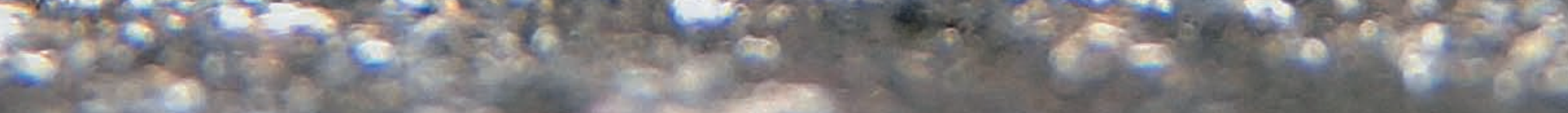

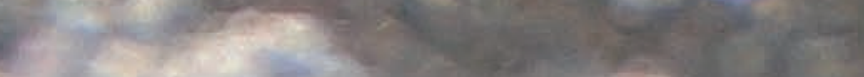




\section{POUCA IDADE E MUITA COMPETÊNCIA}

\section{Pioneira na América Latina, a}

\section{Empresa Júnior da FGV-EAESP há}

\section{2 anos alavanca carreiras e negócios}

Desde 1988, a EAESP sedia uma experiência pioneira e bem-sucedida: a EJ-FGV, primeira empresa júnior da América Latina. O Brasil hoje é o país que mais possui empresas juniores do mundo, com aproximadamente mil delas, vinculadas sobretudo a cursos de graduação em ciências sociais aplicadas como Administração, Economia e Contabilidade. A seguir, relatamos exemplos de resultados que a EJ-FGV, veterana nesse mercado, tem propiciado a empresas clientes, bem como benefícios para a formação de futuros administradores.

ÓTICA DO CLIENTE. Nos últimos 12 meses, a B2P, empresa especializada em estruturar programas de melhoria de qualidade de vida de funcionários de grandes companhias, aumentou seu faturamento em 30\% e dobrou o número de colaboradores, preparando-se para crescer ainda mais nos próximos anos.

Não se trata apenas de otimismo, mas de um plano de expansão ancorado no mapeamento do potencial do mercado e numa estratégia de investir na capacitação de recursos humanos. "Não tenho dúvidas em atribuir o crescimento que estamos conseguindo às mudanças e ao planejamento que implementamos a partir da consultoria de alunos da EAESP, por meio da EJ-FGV", diz categoricamente o dono da B2P, Oswaldo Mervach. "Encomendamos um business plan e recebemos um trabalho com uma sofisticação metodológica que excedeu todas as expectativas. Eles pesquisaram profundamente o mercado para entender onde poderíamos nos posicionar e fizeram análises que reorientaram toda nossa atuação".

O grande dilema da B2P era saber se contratava mais gente para crescer, o que elevaria os custos, ou se primeiro conquistava novos clientes. "Se conseguíssemos novos clientes, correríamos o risco de não conseguir atendê-los porque, como nosso produto é único, 


\section{BRASIL É O PAÍS COM MAIS EMPRESAS JUNIORES DO MUNDO Por Simone Biehler Mateos}

A primeira empresa júnior do mundo surgiu na França, em 1967, na École Supérieure des Sciences Économiques et Commerciales de Paris. Sua característica básica era ser uma associação civil sem fins lucrativos, constituída e gerida exclusivamente por alunos de graduação com o objetivo de complementar sua formação, desenvolvendo aptidões profissionais por meio da prestação de serviços e elaboração de projetos para empresas e entidades, sempre com a supervisão de professores.

A ideia logo foi imitada por outras escolas francesas em cursos de Engenharia, Administração, Comunicação, Agronomia e outros. Em 1969, 20 empresas formaram a Confederação Francesa de Empresas Juniores. A iniciativa, desde então, espalhou-se mundo afora. Embora as primeiras tenham surgido vinculadas a um só curso, algumas empresas juniores, hoje, aglutinam alunos de diferentes áreas.

No Brasil, a ideia chegou em 1988 por iniciativa da Câmara de Comércio Brasil-França. A pioneira foi a EJ-FGV e em seguida, também em São Paulo, surgiram a Empresa Júnior FAAP e a Júnior Poli Estudos.

Hoje estima-se que os cerca de mil empreendimentos existentes aglutinam 23 mil estudantes, o que torna o Brasil o país com maior atuação de empresas juniores no mundo. Existem federações dessas empresas em 11 estados e no Distrito Federal e, desde 2003, o movimento organizou uma confederação - a Brasil Júnior - que hoje congrega 144 empresas. Segundo levantamento da Brasil Júnior, naquele ano, as empresas confederadas tiveram faturamento de $R \$ 4,5$ milhões, quase um terço dele concentrado em São Paulo.

Ainda segundo a Brasil Júnior, nove em cada dez empresas juniores foram criadas por iniciativa espontânea dos alunos, sendo $60 \%$ vinculadas a universidades públicas. Cerca de metade desses empreendimentos são das áreas de ciências sociais aplicadas (sobretudo em Administração, Economia e Contabilidade), 30\% são da área de exatas (com destaque para as engenharias), $10 \%$ da área de biológicas e 10\% multidisciplinares. temos de investir ao menos seis meses num profissional antes que ele seja realmente produtivo", explica Mervach.

Segundo ele, com a consultoria da EJ-FGV, a B2P conseguiu elaborar um plano de crescimento paulatino e gradual. "Eles nos deram uma visão mais ampla do mercado, nos ajudaram a identificar nichos e focar melhor nosso clientealvo", conta o empresário. "Estamos crescendo de forma sustentável e, se tudo der certo, em dois ou três anos contrataremos a EJ-FGV novamente para planejar outra mudança de patamar", diz o empresário.

Esse entusiasmo é comum entre os clientes da EJ-FGV. A editora Anotações com Arte, por exemplo, já contratou os seus serviços duas vezes em menos de um ano. "A partir do estudo de mercado que eles fizeram, ampliamos nossa base de clientes e, com a nova ferramenta de gestão financeira desenvolvida no segundo projeto, melhoramos muito nosso planejamento", conta Monique Mendonça, sócia da editora. "O profissionalismo e o alto nível da equipe da EJ-FGV nos surpreendeu muito, sobretudo porque eles são extremamente jovens. Hoje recomendo os serviços da EJ-FGV aos meus clientes de todos os portes", conclui.

De fato, a despeito de desenvolver projetos principalmente para microempreendedores, a EJ-FGV tem entre seus clientes empresas de todos os tamanhos. Recentemente, por exemplo, foi contratada para estruturar um projeto de responsabilidade social para a fábrica do laboratório farmacêutico Boehringer Ingelheim.

Curioso é que, entre os satisfeitos, incluem-se também empreendedores que tinham um projeto de empresa e desistiram dele depois de estudos de viabilidade feitos pela EJ-FGV. Ficam felizes de poder investir em outra ideia sem ter de amargar o fracasso da primeira.

FORMAÇÃO DE ADMINISTRADORES. Boa para os clientes, as empresas juniores costumam trazer também um grande diferencial à formação e ao currículo dos alunos que nelas trabalham. "É um aprendizado impossível de se ter só em sala de aula porque aqui tudo tem de ser realizável, os projetos têm de ser adequados à realidade do cliente, às suas limitações, o que muitas vezes exige adaptar ferramentas teóricas de gestão. 
Aprendemos muito sobre o mercado e sobre os problemas enfrentados na prática pelas empresas", explica Daniel Lencioni, aluno da EAESP e diretor de consultoria da EJ-FGV.

Camila Key, diretora de marketing, concorda e destaca outros aspectos: "A gente aprende a trabalhar em equipe para analisar problemas e buscar soluções, a se comunicar e se apresentar melhor. Sinto isso claramente agora que estou me apresentando para seleções de estagiários".

\section{A EJ-FGV possui clientes de todos os tamanhos e já desenvolveu mais de 500 projetos de consultoria}

A diferença é sentida também pelos professores: "Os alunos que participam da Empresa Júnior têm uma desenvoltura muito maior nas apresentações, e um desempenho bem superior na minha disciplina, que é de Estratégia", avalia o conselheiro da EJ-FGV e professor da EAESP, Marco Aurélio Queiroz. "No segundo semestre do curso comecei a demandar dos professores conhecimentos que só seriam dados no sexto ou oitavo semestres. O envolvimento com projetos reais é um estímulo sem igual", acrescenta o presidente da EJ-FGV, Gabriel Porlan.

PORTFÓLIO E PROCESSOS. Em seus 22 anos de existência, a empresa júnior da EAESP já desenvolveu mais de 500 projetos de consultoria, incluindo desde estudos de viabilidade para projetos de empresas que ainda não existiam, até sofisticados planos para o aprimoramento da gestão de alguma área específica em grandes companhias. Muitos projetos voltaram-se à implementação de sistemas de gestão para a obtenção de selos ISO.

Com um detalhado banco de dados sobre todos os projetos já desenvolvidos, a EJ-FGV consegue preservar sua experiência acumulada, a despeito da alta rotatividade de seus membros que, por serem alunos de graduação, costumam permanecer na empresa em média dois anos apenas, além de terem, em sua maioria, entre 19 e 22 anos.

Nesse contexto, a prestação de serviços de alta qualidade por profissionais jovens e em formação está ancorada em uma série de procedimentos aprimorados ao longo de duas décadas. Primeiro, para entrar na empresa é preciso passar por uma rigorosa seleção. Geralmente, de 250 a 300 candidatos, apenas 20 são admitidos a cada semestre. Todos passam por várias capacitações oferecidas por empresas parceiras. Uma das principais é a McKinsey \& Co., uma das maiores companhias de consultoria estratégica do mundo, que repassa aos participantes da EJ-FGV sua metodologia de trabalho. "É com as ferramentas da McKinsey que analisamos os problemas das empresas que nos contratam e estruturamos todo o nosso trabalho", explica Camila.

Outro parceiro é a MBA Empresarial, uma consultoria de recursos humanos com 20 anos de experiência no mercado. Ela oferece à EJ-FGV treinamentos em liderança, trabalho em equipe, autodesenvolvimento e técnicas de negociação, além de ajudar na estruturação de um processo seletivo novo a cada seis meses. "Isso exige que eles analisem qual é o perfil de profissional de que a empresa júnior está precisando mais naquele momento, e que aprendam técnicas de entrevista, de dinâmica de grupo e de avaliação de competências", explica Sandra Betti, da MBA.

Outra regra é que todos devem implementar, primeiro, um ou mais projetos de aprimoramento de gestão na própria empresa júnior, antes de participar de consultorias externas. "Os alunos investem muito em melhorar os próprios processos internos, o que é um excelente treinamento porque a empresa júnior funciona como qualquer outra: com faturamento, despesas, metas e planejamento estratégico, e tendo de fechar as contas. A única diferença é que os membros não são remunerados, e todo o lucro é reinvestido em treinamentos e no aprimoramento da sua gestão", explica o professor Marco Queiroz. Outro cuidado importante é que os projetos são bem analisados antes de serem aceitos: "Quando um projeto de consultoria demanda competências nas quais os membros não se sentem muito seguros, o desafio só é aceito depois que eles conseguem o compromisso de contar com a assessoria de algum professor com expertise na área", explica Queiroz.

SIMONE BIEHLER MATEOS,

jornalista, simonemateos@gmail.com 